\title{
Social and behavioral health responses to COVID-19: lessons learned from four decades of an HIV pandemic
}

\author{
Lisa A. Eaton ${ }^{1} \cdot$ Seth C. Kalichman ${ }^{2}$
}

Received: 6 April 2020 / Accepted: 16 April 2020 / Published online: 25 April 2020

(C) Springer Science+Business Media, LLC, part of Springer Nature 2020

\begin{abstract}
Our public health approaches to addressing COVID-19 are heavily dependent on social and behavioral change strategies to halt transmissions. To date, biomedical forms of curative and preventative treatments for COVID-19 are at best limited. Four decades into the HIV epidemic we have learned a considerable amount of information regarding social and behavioral approaches to addressing disease transmission. Here we outline broad, scoping lessons learned from the HIV literature tailored to the nature of what we currently know about COVID-19. We focus on multiple levels of intervention including intrapersonal, interpersonal, community, and social factors, each of which provide a reference point for understanding and elaborating on social/behavioral lessons learned from HIV prevention and treatment research. The investments in HIV prevention and treatment research far outweigh any infectious disease in the history of public health, that is, until now with the emergence of COVID-19.
\end{abstract}

With our existing healthcare infrastructure we are currently unable to clinically manage the onslaught of coronavirus disease 2019 (COVID-19). Existing vaccine development platforms have rendered an 18-month optimistic timeframe for broad-reaching biomedical approaches to prevention (Coreil, 2013). Avenues for prevention and treatment outside of an effective vaccine will, therefore, invariably rely on changing social/behavioral patterns (e.g., physical distancing and selfisolation) for containing the spread of disease. The extent to

Lisa A. Eaton

lisa.eaton@uconn.edu

1 Human Development and Family Sciences, University of Connecticut, Storrs, CT, USA

2 Psychological Sciences, University of Connecticut, Storrs, CT, USA which public health response must rely on behavioral and social factors for disease prevention varies greatly depending on disease transmission factors (e.g., mode of disease transmission, rapid travel and trade patterns, economic and health care infrastructure stability). Unfortunately, COVID-19, has presented itself as a formidable agent posing multiple unique challenges. As a novel virus with no residual immunity from prior exposure, herd immunity can't be relied upon to halt social networks of disease transmission. COVID-19 is highly contagious, with multiple transmissions occurring per one contagious person (reproduction rate) during the early stage of outbreak - a relatively elevated rate compared with many other infectious diseases (Zhang et al., 2020). COVID-19 infections initially present with symptoms that are mostly indistinguishable from other viral diseases, stalling early detection. Furthermore, with no curative option, treatment is focused on symptom management.

The current state of COVID-19 disease transmission has left our public health approaches to be heavily dependent on social and behavioral change strategies to halt transmissions. Although different from the social and behavioral dynamics of transmission and pathogenesis, HIV infection offers lessons learned for those who are embarking on this area of research for preventing the spread of COVID-19. Almost 40 years after the first cases of AIDS were identified in the US, and with still no effective vaccine, we have learned a considerable amount about the reliance on social and behavioral approaches to slowing infectious disease. The investments in HIV prevention and treatment research far outweigh any infectious disease in the history of public health, that is, until now with the emergence of COVID-19. Here we outline broad, scoping lessons learned from the HIV epidemic tailored to the nature of what we currently know about COVID-19. As a unifying framework, we posit that the Social Ecological Model of Health (Hanson et al., 
2005) may prove useful as it attends to levels of intervention that may serve to frame responses to COVID-19. The model has multiple foci, including intrapersonal, interpersonal, community, and social factors, each of which provide a reference point for understanding and elaborating on social/behavioral lessons learned from HIV prevention and treatment research.

\section{Intrapersonal factors}

Sustained, individual-level, behavioral change is challenging to achieve. Interventions targeting individual-level behavior change have remained a cornerstone of HIV prevention (Herbst et al., 2005; Crepaz et al., 2007; Johnson et al., 2006). There exist critical threads of similarity in our current COVID-19 prevention strategies to efforts aimed at stemming HIV transmission. Interventions to alter the behavioral patterns of individuals can have important and substantive impact on risk reduction and disease outcomes, but are likely not sufficient for disease eradication. Further, it has long been known in HIV prevention and treatment research that intervention effects to alter behavioral patterns can vary greatly across populations and that sub-populations in greatest need of support for changing behavioral patterns are also most likely to experience barriers to accessing support (Faugier \& Sargeant, 1997). COVID-19 prevention efforts are currently largely dependent on individual-level behavior change, including self-isolation and physical distancing, to an unprecedented scale. We know from HIV prevention and treatment research that information, motivation, and behavioral skills are key to initiating behavior change, but are unlikely sufficient for sustained change if only individual components are addressed (Fisher et al., 2006). Changes in behavioral patterns are challenging to maintain overtime and, similar to many vaccines, may rely on booster sessions to support (Eaton et al., 2013). Limitations to maintaining altered behavioral patterns are observed across a broad spectrum of health behavior change and rely on multi-level intervention approaches (see below) (Summers \& Curtis, 2020; Wiltink et al., 2007).

Medical mistrust and conspiracy beliefs undermine datadriven public health interventions. Uptake of effective HIV treatment advances has long been stymied by underlying mistrust of health care and conspiracy beliefs regarding the origin of HIV, the existence and characteristics of the virus itself, and the purpose and impact of antiretroviral medications (Kalichman, 2009; Bogart \& Bird, 2003; Eaton et al., 2017). Mistrust of governmental initiatives to implement public health interventions are largely based on a history of abuse of vulnerable populations (e.g., Tuskegee syphilis experiment) (Bogart \& Thorburn, 2005) and racial/ethnic discrimination documented within health care infrastructure
(Obermeyer et al., 2019). However, new social influences, primarily driven by more general anti-science and antigovernment forces, are impacting COVID-19 containment efforts (Dyer, 2020). Social media is used to distribute messages warning that COVID-19 does not exist, that it is harmless, that is manmade, that a cure exists and is being withheld by the government, that it is being used to justify an imminent 'police state', etc. (Butler, 2020). These conspiracy-driven messages are all well-documented lines of thought in HIV social science research, and critically, result in harmful outcomes (Nattrass, 2012; Kalichman, 2017). We have observed in HIV research that conspiracy beliefs tend to be driven by a rejection of authority (i.e., as a political ideology) or as a psychological state of paranoia (Kalichman, 2009). Most critically, we know that poor political leadership results in highly fertile social foundations for developing conspiracy theories towards public health initiatives (Nattrass, 2012). There is likely no better example of the destructive power of conspiracy thinking on public health than the history of the HIV epidemic in South Africa during the presidency of Thabo Mbeki. It is estimated that 330,000 individuals died due to lack of HIV treatment and 35,000 infants were born with HIV as a result of conspiracy driven public health programing (Chigwedere et al., 2008). The need to combat anti-science rhetoric and conspiracy thinking in the era of COVID-19 has been apparent since its first days in right-wing media and anti-vaccine activists' propaganda (Depoux et al., 2020; Garfin et al., 2020; Li et al., 2020; Llewellyn, 2020), and failure to squelch the seeds of mistrust will be paid in the cost of human life.

\section{Interpersonal factors}

Social stigma of HIV is grounded in racism, homophobia, and sexism, and the stigmatization of COVID-19 has already occurred. Social stigma is complex and omnipresent, and acts as a driver of social hierarchy. The extent to which social stigma has weakened efforts to slow HIV transmission is challenging to quantify, however, it is acknowledged as one of the most formidable social factors working against HIV prevention and treatment (Brent, 2016). Stigma in HIV social science literature is viewed as a process where individuals living with HIV experience status loss as a result of their HIV positive status (Goffman, 1963). Those who experience stigma are devalued, ostracized, and ignored (Goffman, 1963; Link \& Phelan, 2001). In the case of COVID-19, elements of social stigma and social hierarchy are currently unfolding. Elderly and individuals with compromised immune systems have elevated morbidity and mortality related to COVID-19 relative to other groups. Political discussion is rife regarding the social tipping point of protecting populations viewed as most vulnerable (e.g., 
advocacy for the need to protect all human life (McKinley \& Goldmacher, 2020) vs advocacy for weighing the value of human life (Rodriguez, 2020)). These actions effectively create an in-group vs out-group mentality, or social hierarchy, and have detrimental impacts on public health measures (Nyblade et al., 2009). The establishment of in-groups versus out-groups perpetuates the devaluing of out-group members, bolsters disproportionate power and influence of in-group members, and is used as a justification for the mistreatment and disregard of out-group members (Link \& Phelan, 2001). For example, the use of the phrase "Chinese virus" (Rogers et al., 2020) for COVID-19 serves to establish social dominance, blame, and social delineation, all justifications for acts of discrimination, in this case, against people of Asian heritage (Person et al., 2004). Approaches to addressing stigma in the context of promoting well-being and disease prevention exist and likely provide relevant tools applicable to addressing COVID-19. Interventions to address stigma have been developed that target individuals, health care workers, communities, and social figures, which will likely find new purpose in COVID-19 (Andersson et al., 2020; Rao et al., 2019; Stangl et al., 2013).

\section{Community}

HIV infection is not an isolated, unidimensional disease, it co-occurs and interacts with other social concerns. Research on the HIV pandemic has long established that HIV co-occurs with multiple intersecting epidemics, creating what Singer termed a syndemic (Singer \& Clair, 2003). Individuals experiencing mental health and substance abuse problems, food insecurity, housing instability, and overall social marginalization are the most vulnerable to HIV, and HIV infection perpetuates these co-occurring conditions (Robinson et al., 2016; Walters et al., 2020; Turpin et al., 2020; The, 2020). While the transmission of COVID-19 is, of course, markedly different from HIV, there needs to be heightened concern for communities most afflicted by poverty, high population density, barriers to physical distancing, and limited access to health care and other resources-these factors will amplify vulnerability to COVID-19. In turn, we should expect COVID-19 to exacerbate mental health problems and substance abuse by cutting off social support, increasing stress, further reducing access to services, and impeding healthcare among individuals living in poverty and possessing limited personal agency and social capital (Stein, 2020).

Multi-level community interventions yield more robust and sustainable outcomes than single-level efforts to prevent $H I V$ transmission. Initial social/behavioral interventions to slow HIV transmission largely prioritized the changing of individual level behavior (Johnson et al., 2009). The field evolved, however, to acknowledge that individual behavior is heavily influenced by the broader social and structural systems wherein behavior occurs (IOM, 1995), and the need to develop multi-level interventions capable of addressing multiple systems that influence behavior (e.g., health care providers, employment, personal safety, health care access) was prioritized (Blankenship et al., 2006; Des Jarlais, 2000). In the context of COVID-19, the most pressing social/behavioral component to containment appears to be physical distancing and hygiene strategies. Social influence models of behavior change have proven effective in changing and sustaining changes in behavior by shifting social norms and reinforcing risk reduction efforts (Kelly et al., 1997, 2006; Latkin et al., 2009). While these models have relied on face-to-face interactions as the vehicle of change, they have been translated to online platforms that are immediately implementable for sustaining measures to contain and mitigate COVID-19 (Green et al., 2015; Marhefka et al., 2012, 2013, 2014; Young et al., 2014; Rice et al., 2012; Chiu \& Young, 2015). Examples of multi-level interventions to impact these practices include messaging to promote social distancing and good hygiene behaviors (individuallevel behavior change, delivered at the community-level), the closing of schools and non-essential business services (structural-level), and the increased availability of sanitizing products (e.g., hand sanitizer, disinfectant wipes) in public spaces (structural- and social-level). Multi-level interventions pose multiple assessment and implementation related challenges, but have the potential for high efficacy in altering the course of disease (Auerbach, 2009).

\section{Society}

Community Mobilization for Disease Prevention. Engaging multiple societal sectors to address health, social, or environmental issues is the cornerstone of community or social mobilization (UNAIDS, 1997). As outlined by Lippman et al. (2013) critical components of community mobilization include: a defined or shared concern, critical consciousness regarding the concern, organizational structure with links to groups/networks, individual or institutional leadership, collective/shared activities and actions, and social cohesion. Across the history of HIV in the US there exist multiple instances of community mobilization efforts (Coates et al., 2014) beneficially impacting the lives of people affected by HIV. Similar to what we are currently observing with COVID-19, community mobilization efforts to address HIV have typically focused on changing federal level responses. Particularly in the earliest days of the HIV epidemic in the US, community mobilization efforts were ultimately highly effective at challenging and changing the response to HIV at the federal level (UNAIDS, 1997). But efforts 
were sustained and hard fought. We are observing similar patterns with COVID-19 where communities most affected (e.g. high population density cities and communities initially impacted) are appealing to the broader community for a national level response.

\section{Conclusion}

HIV emerged as a global threat to public health more than 40 years prior to COVID-19, and while the lack of public health preparedness for the current pandemic is well recognized (Carinci, 2020), social and behavioral scientists aiming to contribute to the containment and mitigation of COVID-19 will be well-served by the lessons we have learned in HIV prevention and treatment research. Preventing the worst care scenarios of COVID-19 morbidity and mortality can be achieved through intrapersonal, interpersonal, community, and societal levels of data-driven and well-coordinated interventions. HIV prevention and treatment sciences has not always achieved these goals, but the lessons we have learned should be evaluated for use in the case of COVID-19 and for future pandemics.

\section{References}

Andersson, G. Z., Reinius, M., Eriksson, L. E., et al. (2020). Stigma reduction interventions in people living with HIV to improve health-related quality of life. Lancet HIV, 7, e129-e140.

Auerbach, J. (2009). Transforming social structures and environments to help in HIV prevention. Health Affairs, 28, 1655-1665.

Blankenship, K. M., Friedman, S. R., Dworkin, S., \& Mantell, J. E. (2006). Structural interventions: Concepts, challenges and opportunities for research. Journal of Urban Health, 83, 59-72.

Bogart, L. M., \& Bird, S. T. (2003). Exploring the relationship of conspiracy beliefs about HIV/AIDS to sexual behaviors and attitudes among African-American adults. Journal of the National Medical Association, 95, 1057-1065.

Bogart, L. M., \& Thorburn, S. (2005). Are HIV/AIDS conspiracy beliefs a barrier to HIV prevention among African Americans? Journal of Acquired Immune Deficiency Syndromes, 38, 213-218.

Brent, R. J. (2016). The value of reducing HIV stigma. Social Science and Medicine, 151, 233-240.

Butler, K. (2020). "A Fake Pandemic": Anti-Vaxxers are spreading coronavirus conspiracy theories. Retrieved April 5, 2020 from https://www.motherjones.com/politics/2020/03/a-fake-pandemicantivaxxers-are-spreading-coronavirus-conspiracy-theories/.

Carinci, F. (2020). Covid-19: Preparedness, decentralisation, and the hunt for patient zero. BMJ, 368, bmj m799.

Chigwedere, P., Seage, G. R., 3rd, Gruskin, S., Lee, T. H., \& Essex, M. (2008). Estimating the lost benefits of antiretroviral drug use in South Africa. Journal of Acquired Immune Deficiency Syndromes, 49, 410-415.

Chiu, C. J., \& Young, S. D. (2015). The relationship between online social network use, sexual risk behaviors, and hiv sero-status among a sample of predominately african american and latino men who have sex with men (MSM) social media users. AIDS and Behaviour, 19, 98-105.
Coates, T. J., Kulich, M., Celentano, D. D., et al. (2014). Effect of community-based voluntary counselling and testing on HIV incidence and social and behavioural outcomes (NIMH Project Accept; HPTN 043): A cluster-randomised trial. The Lancet Global Health, 2, e267-277.

Coreil, J. (2013). Social and behavioral foundations of public health (2nd ed.). Thousand Oaks: Sage Publications.

Crepaz, N., Horn, A. K., Rama, S. M., et al. (2007). The efficacy of behavioral interventions in reducing HIV risk sex behaviors and incident sexually transmitted disease in black and Hispanic sexually transmitted disease clinic patients in the United States: A meta-analytic review. Sexually Transmitted Diseases, 34, 319-332.

Depoux, A., Martin, S., Karafillakis, E., Bsd, R. P., Wilder-Smith, A., \& Larson, H. (2020). The pandemic of social media panic travels faster than the COVID-19 outbreak. Journal of Travel Medicine.

Des Jarlais, D. C. (2000). Structural interventions to reduce HIV transmission among injecting drug users. AIDS, 14, S41-46.

Dyer, O. (2020). Trump claims public health warnings on covid-19 are a conspiracy against him. BMJ, 368, m941.

Eaton, L. A., Kalichman, S. C., Kenny, D. A., \& Harel, O. (2013). A reanalysis of a behavioral intervention to prevent incident HIV infections: Including indirect effects in modeling outcomes of Project EXPLORE. AIDS Care, 25, 805-811.

Eaton, L. A., Kalichman, S. C., Price, D., Finneran, S., Allen, A., \& Maksut, J. (2017). Stigma and conspiracy beliefs related to preexposure prophylaxis (PrEP) and interest in using PrEP among black and white men and transgender women who have sex with men. AIDS and Behavior, 21, 1236-1246.

Faugier, J., \& Sargeant, M. (1997). Sampling hard to reach populations. Journal of Advanced Nursing, 26, 790-797.

Fisher, J. D., Fisher, W. A., Amico, K. R., \& Harman, J. J. (2006). An information-motivation-behavioral skills model of adherence to antiretroviral therapy. Health Psychology, 25, 462-473.

Garfin, D. R., Silver, R. C., \& Holman, E. A. (2020). The novel coronavirus (COVID-2019) outbreak: Amplification of public health consequences by media exposure. Health Psychology, 39(5), $355-357$.

Goffman, I. (1963). Stigma: Notes on the management of spoiled identity. New York: Simon \& Schuster.

Green, S. M., Lockhart, E., \& Marhefka, S. L. (2015). Advantages and disadvantages for receiving Internet-based HIV/AIDS interventions at home or at community-based organizations. AIDS Care, 27, 1304-1308.

Hanson, D., Hanson, J., Vardon, P., et al. (2005). The injury iceberg: An ecological approach to planning sustainable community safety interventions. Health Promotion Journal of Australia, 16, 1.

Herbst, J. H., Sherba, R. T., Crepaz, N., et al. (2005). A meta-analytic review of HIV behavioral interventions for reducing sexual risk behavior of men who have sex with men. JAIDS Journal of Acquired Immune Deficiency Syndromes, 39, 228-241.

IOM. (1995). Institute of Medicine. Assessing the Social and Behavioral Science Base for HIV/AIDS Prevention and Intervention: Workshop Summary. Washington (DC).

Johnson, B. T., Carey, M. P., Chaudoir, S. R., \& Reid, A. E. (2006). Sexual risk reduction for persons living with HIV: Research synthesis of randomized controlled trials, 1993 to 2004. Journal of Acquired Immune Deficiency Syndromes, 41, 642-650.

Johnson, B. T., Scott-Sheldon, L. A., Smoak, N. D., Lacroix, J. M., Anderson, J. R., \& Carey, M. P. (2009). Behavioral interventions for African Americans to reduce sexual risk of HIV: A meta-analysis of randomized controlled trials. Journal of Acquired Immune Deficiency Syndromes, 51, 492-501.

Kalichman, S. C. (2009). Denying AIDS: Conspiracy theories, pseudoscience, and human tragedy. Berlin: Springer. 
Kalichman, S. C. (2017). Pence, putin, mbeki and their HIV/AIDSrelated crimes against humanity: Call for social justice and behavioral science advocacy. AIDS and Behavior, 21, 963-967.

Kelly, J. A., Amirkhanian, Y. A., Kabakchieva, E., et al. (2006). Prevention of HIV and sexually transmitted diseases in high risk social networks of young Roma (Gypsy) men in Bulgaria: Randomised controlled trial. British Medical Journal, 333, 1098.

Kelly, J. A., Murphy, D. A., Sikkema, K. J., et al. (1997). Randomised, controlled, community-level HIV-prevention intervention for sexual-risk behaviour among homosexual men in US cities. Community HIV Prevention Research Collaborative. Lancet, 350, $1500-1505$.

Latkin, C. A., Donnell, D., Metzger, D., et al. (2009). The efficacy of a network intervention to reduce HIV risk behaviors among drug users and risk partners in Chiang Mai, Thailand and Philadelphia, USA. Social Science and Medicine, 68, 740-748.

Li, C., Chen, L. J., Chen, X., Zhang, M., Pang, C. P., \& Chen, H. (2020). Retrospective analysis of the possibility of predicting the COVID-19 outbreak from Internet searches and social media data, China, 2020. Euro Eurosurveillance, 25, 2000199.

Link, B., \& Phelan, J. (2001). Conceptualizing stigma. Annual Review of Sociology, 27, 363-385.

Lippman, S. A., Maman, S., MacPhail, C., et al. (2013). Conceptualizing community mobilization for HIV prevention: Implications for HIV prevention programming in the African context. PLoS ONE, 8, e78208.

Llewellyn, S. (2020). Covid-19: How to be careful with trust and expertise on social media. BMJ, 368, 1160 .

Marhefka, S. L., Buhi, E. R., Baldwin, J., et al. (2014). Effectiveness of healthy relationships video-group-A videoconferencing group intervention for women living with HIV: Preliminary findings from a randomized controlled trial. Telemedicine and e-Health, 20, 128-134.

Marhefka, S. L., Fuhrmann, H. J., Gilliam, P., Lopez, B., \& Baldwin, J. (2012). Interest in, concerns about, and preferences for potential video-group delivery of an effective behavioral intervention among women living with HIV. AIDS and Behavior, 16, 1961-1969.

Marhefka, S. L., Iziduh, S., Fuhrmann, H. J., et al. (2013). Internetbased video-group delivery of Healthy Relationships-a "prevention with positives" intervention: Report on a single group pilot test among women living with HIV. AIDS Care, 25, 904-909.

McKinley, J., \& Goldmacher, S. (2020). How cuomo, once on sidelines, became the politician of the moment. New York Times. Retrieved April 5, 2020 from https://www.nytimes.com/2020/03/24/nyreg ion/governor-andrew-cuomo-coronavirus.html.

Nattrass, N. (2012). The AIDS conspiracy: Science fights back. Columbia: Columbia University Press.

Nyblade, L., Stangl, A., Weiss, E., \& Ashburn, K. (2009). Combating HIV stigma in health care settings: What works? Journal of the international AIDS Society, 12, 15.

Obermeyer, Z., Powers, B., Vogeli, C., \& Mullainathan, S. (2019). Dissecting racial bias in an algorithm used to manage the health of populations. Science, 366, 447-453.

Person, B., Sy, F., Holton, K., Govert, B., \& Liang, A. (2004). National center for inectious diseases SCOT: Fear and stigma: the epidemic within the SARS outbreak. Infectious Diseases, 10, 358-363.

Rao, D., Elshafei, A., Nguyen, M., Hatzenbuehler, M. L., Frey, S., \& Go, V. F. (2019). A systematic review of multi-level stigma interventions: State of the science and future directions. BMC Medicine, 17, 41.

Rice, E., Tulbert, E., Cederbaum, J., Barman Adhikari, A., \& Milburn, N. G. (2012). Mobilizing homeless youth for HIV prevention: A social network analysis of the acceptability of a face-to-face and online social networking intervention. Health Education Research, 27, 226-236.
Robinson, A. C., Knowlton, A. R., Gielen, A. C., \& Gallo, J. J. (2016). Substance use, mental illness, and familial conflict non-negotiation among HIV-positive African-Americans: Latent class regression and a new syndemic framework. Journal of Behavioral Medicine, 39, 1-12.

Rodriguez, A. (2020). Texas' lieutenant governor suggests grandparents are willing to die for US economy. Retrieved April 5, 2020 from https://www.usatoday.com/story/news/nation/2020/03/24/ covid-19-texas-official-suggests-elderly-willing-die-econo my/2905990001/.

Rogers, K., Jakes, L., \& Swanson, A. (2020). Trump defends using 'Chinese Virus' label, ignoring growing criticism. The New York Times. Retrieved April 5, 2020 from https://www.nytim es.com/2020/03/18/us/politics/china-virus.html.

Singer, M., \& Clair, S. (2003). Syndemics and public health: Reconceptualizing disease in bio-social context. Medical Anthropology Quarterly, 17, 423-441.

Stangl, A. L., Lloyd, J. K., Brady, L. M., Holland, C. E., \& Baral, S. (2013). A systematic review of interventions to reduce HIVrelated stigma and discrimination from 2002 to 2013: How far have we come? Journal of the International AIDS Society, 16, 18734.

Stein, R. (2020). COVID-19 and rationally layered social distancing. International Journal of Clinical Practice. https://doi. org/10.1111/ijcp.13501.

Summers, C., \& Curtis, K. (2020). Novel Digital architecture of a "Low Carb Program" for initiating and maintaining long-term sustainable health-promoting behavior change in patients with type 2 diabetes. JMIR Diabetes, 5, e15030.

The, L. H. (2020). The syndemic threat of food insecurity and HIV. Lancet HIV, 7, e75.

Turpin, R., Slopen, N., Boekeloo, B., Dallal, C., Chen, S., \& Dyer, T. (2020). Testing a syndemic index of psychosocial and structural factors associated with HIV testing among black men. Journal of Health Care for the Poor and Underserved, 31, 455-470.

UNAIDS. (1997). Community Mobilization and AIDS. Retrieved April 5, 2020 from http://data.unaids.org/publications/irc-pub03 /commmob-tu_en.pdf.

Walters, S. M., Braksmajer, A., Coston, B., et al. (2020). A syndemic model of exchange sex among hiv-positive men who have sex with men. Archives of Sexual Behavior. https://doi.org/10.1007/ s10508-020-01628-8.

Wiltink, J., Dippel, A., Szczepanski, M., Thiede, R., Alt, C., \& Beutel, M. E. (2007). Long-term weight loss maintenance after inpatient psychotherapy of severely obese patients based on a randomized study: Predictors and maintaining factors of health behavior. Journal of Psychosomatic Research, 62, 691-698.

Young, S. D., Holloway, I., Jaganath, D., Rice, E., Westmoreland, D., \& Coates, T. (2014). Project HOPE: Online social network changes in an HIV prevention randomized controlled trial for African American and Latino men who have sex with men. American Journal of Public Health, 104, 1707-1712.

Zhang, S., Diao, M., Yu, W., Pei, L., Lin, Z., \& Chen, D. (2020). Estimation of the reproductive number of novel coronavirus (COVID19) and the probable outbreak size on the Diamond Princess cruise ship: A data-driven analysis. International Journal of Infectious Diseases, 93, 201-204.

Publisher's Note Springer Nature remains neutral with regard to jurisdictional claims in published maps and institutional affiliations. 